\title{
Selection of lactic acid bacteria as candidate probiotics and in vivo test on Artemia nauplii
}

\author{
Faouzi Lamari ${ }^{1,2}$, Khouadja Sadok ${ }^{2}$, Amina Bakhrouf ${ }^{2}$, François-Joël Gatesoupe ${ }^{3,{ }^{*}}$
}

\author{
1 UMR 6539 LEMAR, Laboratoire "Adaptation, Reproduction, Nutrition” (ARN), Centre de Brest, Ifremer, BP 70, \\ 29280, Plouzané, France \\ ${ }^{2}$ Faculty of Pharmacy, Laboratoire "Analyse, Traitement et Valorisation des Polluants de l'Environnement et des \\ Produits", rue Avicenne, 5000, Monastir, Tunisia \\ 3 INRA, UR 1067 "Nutrition, Métabolisme, Aquaculture", Laboratoire ARN, Centre de Brest, Ifremer, BP 70, \\ 29280, Plouzané, France
}

*: Corresponding author : François-Joël Gatesoupe, email address : Joel.Gatesoupe@ifremer.fr

\begin{abstract}
:
Lactic acid bacteria (LAB) were isolated from rotifer cultures in a marine hatchery to search for potential probiotics for marine animals. Fifteen strains were first selected among a total of 55, according to antibacterial activity against Vibrio sp. Among eight strains identified as Lactobacillus casei, four were highly adhesive, suggesting some ability for surface colonization. The other strains were identified as Lactobacillus plantarum, Lactobacillus dextrinicus, and Leuconostoc sp. To validate probiotic potential, Artemia were challenged against pathogenic Vibrio alginolyticus, with or without one of six selected LAB strains. The six strains protected Artemia against the pathogen, to some extent on condition that nutrient enrichment was provided. La. casei BR51 and X2 were preferred, as they were efficient even in the absence of nutrient supply. La. casei X2 was finally selected as candidate probiotic, due to the best growth performances of Artemia, with or without the pathogen.
\end{abstract}

Keywords: 16S Rdna ; Antagonism ; Artemia ; Lactic acid bacteria ; Vibrio

Abbreviations: ARDRA: amplified ribosomal DNA restriction analysis;

Art: Artemia;

Art axe: axenic Artemia;

bp: base pair;

La.: Lactobacillus;

Le.: Leuconostoc;

FASW: filtered and autoclaved sea water;

LAB: lactic acid bacteria;

MRS: De Man, Rogosa, Sharpe;

OD570: optical density at $570 \mathrm{~nm}$;

TSA: tryptic soy agar;

TSB: tryptic soy broth;

V.: Vibrio;

VA: Vibrio alginolyticus;

WHO: World Health Organization. 


\section{Introduction}

Due to the risks of high mortality and infection spread, it is essential to develop disinfection and antimicrobial strategies that could prevent and control bacterial diseases in aquaculture. The massive use of antibiotics may lead to the emergence of resistant bacteria, which can spread in the environment and jeopardize human health (Nomoto, 2005; WHO, 2006). Probiotics are among the most promising alternatives to antibiotics, and the application to aquaculture is now widely accepted (Gomez-Gil et al., 2000; Wang, 2007). Probiotics may enhance health performances, for example by improving the intestinal microbial balance, colonizing the gut, depriving pathogens for adhesion sites, or competing for nutrients (Gatesoupe, 1999). Merrifield et al. (2010) stressed that probiotics must not be pathogenic and should exhibit antagonistic properties towards one or more key pathogens. Most lactic acid bacteria (LAB) are generally recognized as safe, and some species have been extensively studied (Holzapfel et al., 1995). The importance of LAB in fish culture was emphasized by Ring ø and Gatesoupe (1998). A strain presumptively characterized as Lactobacillus plantarum increased the resistance of turbot larvae against pathogenic Vibrio sp. (Gatesoupe, 1994). The interest for LAB as probiotics in aquaculture hatcheries is growing with the recurring evidences of their contribution to maintain a healthy microbial environment in the larval rearing tanks. The choice of an appropriate LAB strain demands critical attention to strain identification and characterization. The application of probiotics must be based on understanding the mechanisms involved and the putative consequences. In this regard, effective probiotics should be aimed against pathogens encountered in hatchery conditions. Marques et al. (2004) reported that Artemia - the most common live food organism - is also particularly suitable as test organism to study the host-microbe interactions. Under gnotobiotic conditions, it is possible to manage microbiota associated to Artemia nauplii, and to evaluate the impact for improving growth and survival (Gordon and Pesti, 1971; Marques et al., 2006).

The aim of this work was to select LAB isolated in our fish hatchery as candidate probiotics for fish larvae. To this end, a first screening of the isolates was based on the protocol proposed by Vine et al. (2006) for selecting intestinal probiotics in marine larviculture. The antimicrobial activity was evaluated in vitro against pathogenic Vibrio. The selected strains were characterized taxonomically, checked for the absence of haemolysin as virulence factor, and tested for adhesiveness to abiotic surfaces. Fjellheim et al. (2010) stressed the importance to combine such methods of screening in vitro with testing in vivo, and the potential of the strains as probiotics was further investigated with a bioassay on Artemia, which was already applied to Bacillus sp. by Mahdhi et al. (2012). 


\section{Materials and methods}

\subsection{Antimicrobial activity of the $L A B$ isolates}

$\mathrm{LAB}$ were isolated from cultures of Brachionus plicatilis in the larval rearing facilities of Ifremer, Centre de Brest. 55 isolates selected after their distinct phenotypic characteristics were tested with an agar well diffusion method, as described by Reinheimer et al. (1990). The bacteria chosen as pathogenic indicators were Vibrio alginolyticus (ATCC 17749; ATCC 33787), and Vibrio parahaemolyticus (ATCC 17802). Six other putative pathogenic isolates were also tested, after characterization as $V$. alginolyticus (32J; 30J; 55J) and $V$. parahaemolyticus (53V; 12pv; 30v) with API 20E strips (Bio-Mérieux). The indicator strains were re-activated overnight in tryptic soy broth (TSB) at $30^{\circ} \mathrm{C}$, and then grown for 24 hours on agar (TSA) at $30^{\circ} \mathrm{C}$. The colonies from pure culture were suspended in $10 \mathrm{~mL}$ of physiological medium and well mixed for $5 \mathrm{~min}$. The suspensions were spread in new TSA plates ( $1 \mathrm{~mL}$ per plate), which were let dry at $27^{\circ} \mathrm{C}$ for $15 \mathrm{~min}$. A sterile $7-\mathrm{mm}$-diameter cork borer was used to cut uniform wells in the agar. The LAB isolates were grown in MRS broth for $24 \mathrm{~h}$ at $37^{\circ} \mathrm{C}$, and after centrifugation and filter sterilization $(0.2 \mu \mathrm{m}), 70 \mu \mathrm{L}$ of the spent culture media were introduced into the wells of the test plates. All the assays were carried out in triplicates. The plates were held at $4^{\circ} \mathrm{C}$ for $2 \mathrm{~h}$, and then incubated at $30^{\circ} \mathrm{C}$. The diameters of the clear zones around the wells were measured after $24 \mathrm{~h}$ of culture.

\subsection{Biochemical characterization of the selected LAB}

The isolates that presented antagonistic activity were characterized by Gram stain, motility, indole production, spore forming, catalase and oxidase activity. Salinity tolerance was evaluated on MRS broths containing $2 \%, 3 \%$ and $6 \% \mathrm{NaCl}$. Exoenzymes production was tested on MRS agar, to which one of the following substrates was added: $0.2 \%$ (wt

$\mathrm{vol}^{-1}$ ) starch for amylase, $1 \%\left(\mathrm{wt} \mathrm{vol}^{-1}\right.$ ) skim milk for caseinase, $1 \%\left(\mathrm{wt} \mathrm{vol}^{-1}\right.$ ) Tween 80 for lipase, $5 \%\left(\mathrm{vol} \mathrm{vol}^{-1}\right)$ egg yolk for phospholipase (lecithinase) and $5 \%\left(\mathrm{vol} \mathrm{vol}^{-1}\right.$ ) fish blood for haemolysin (Ben Kahla-Nakbi et al., 2007). The enzymatic activities were further characterized with the API Zym System (Bio-Mérieux) as described by Papamaloni et al. (2002).

\subsection{Adherence assay}

LAB strains that were cultured in MRS broth were characterized for their ability to form biofilm with a semi-quantitative adherence assay in 96 polystyrene microplates according to Chaieb et al. (2007), with some modifications. An overnight culture in MRS broth at $37^{\circ} \mathrm{C}$ was diluted hundredfold with $2 \%$ glucose in MRS solution (wt vol ${ }^{-1}$ ). Aliquots of 200 $\mu \mathrm{l}$ of the cell suspensions were transferred to U-bottomed 96 wells Microtitre plates (Nunc, Roskilde, Denmark). Each strain was tested in triplicate. Wells with sterile MRS alone were used as controls. The plates were incubated aerobically at $37^{\circ} \mathrm{C}$ for $24 \mathrm{~h}$. The supernatant was discarded and the wells were washed twice to remove the nonadherent cells with PBS (7 mM Na2HPO4, $3 \mathrm{mM} \mathrm{NaH} 2 \mathrm{PO} 4,130 \mathrm{mM} \mathrm{NaCl}$; $\mathrm{pH}$ 7.4). The plates were dried in inverted position. Adherent bacteria were fixed with $95 \%$ ethanol, and stained for 5 min 
with $100 \mu \mathrm{l}$ of crystal violet solution (1\%, Merck). The wells were washed and poured off three times with $300 \mu \mathrm{l}$ of sterile distilled water, and then the plates were air-dried again. The optical density of bacteria at $570 \mathrm{~nm}$ (OD570) was measured with an automated Multiskan reader (Gio de Vita E C., Italy). Adhesion ability was interpreted as highly positive (OD570 $\geq 1)$, moderately to weakly positive $(1>$ OD570 $>0.1)$, or negative (OD570 $\leq 0.1$ ).

\subsection{Phylogenetic characterization}

The LAB were cultivated in MRS agar and incubated at $37^{\circ} \mathrm{C}$ for $24 \mathrm{~h}$. The colonies were collected, and DNA was extracted as described by Lambert et al. (1998), with some modifications (Supplementary Material, Fig. S3). To characterize the amplicons by amplified ribosomal DNA restriction analysis (ARDRA), aliquots of each PCR product were treated with two restriction enzymes, Hae III or Cfo I (Gatesoupe, 2002). One isolate per each dominant cluster was selected, and purified with PCR Clean-Up System kit (Amersham Biosciences, NJ, USA) before partial sequencing the 16S rRNA gene (partial sequences of 896-1037 bp from primer SA-dir) by MilleGen Biotechnologies (Labège, France). The nucleotide sequences obtained were checked with a sequence alignment editor (BioEdit), and homologies were searched with BLAST (NCBI). The sequences were deposited in the EMBL nucleotide sequence database.

\subsection{Challenge test of candidate probiotics with Artemia}

Experiments were performed with Artemia franciscana cysts, originating from Great Salt Lake, Utah, USA (EG® Type, INVE Aquaculture NV, Belgium). Artemia cysts were decapsulated as described by Sorgeloos et al. (1977). Decapsulated cysts were washed nine times with filtered and autoclaved sea water (FASW) over a $50-\mu \mathrm{m}$ sterile filter net. Washed decapsulated cysts were transferred to a sterile falcon containing $30 \mathrm{~mL}$ of FASW. The Falcon were placed on incubator shaker $\left(28^{\circ} \mathrm{C}, 120 \mathrm{rpm}\right)$ and exposed to constant incandescent light. After 18-20 h, ten axenic nauplii were picked up and transferred to sterile falcons containing $30 \mathrm{~mL}$ of FASW. All manipulations were carried out under sterile conditions according to Marques et al. (2004).

The bacterial suspension was added at a density of $10^{6}$ and $10^{7}$ colony forming units $\mathrm{mL}^{-1}$ for the candidate probiotic and the pathogen, Vibrio alginolyticus E3 (ATCC 17749), respectively. Each treatment consisted of three sterile $60-\mathrm{mL}$ falcons. To evaluate the effect of the LAB strains on Artemia, six series of six tests were applied. Each series corresponded to one strain selected for the challenge: 611 , BR743, BR51, X2, BXI, and B31. The series included six conditions of culture: (1) axenic Artemia (Art axe); (2) gnotobiotic culture with the test LAB; (3) culture with the test $L A B$ and a sterilized commercial enrichment product (Red Pepper, Bern Aqua); (4) simple challenge with $V$. alginolyticus (Art+VA); (5) challenge with VA in the presence of the test LAB; (6) challenge with VA in the presence of the test $L A B$ and the enrichment product. The tests lasted 6 days. The commercial enrichment $\left(27.6 \mu \mathrm{g} \mathrm{mL} \mathrm{m}^{-1}\right)$ and the candidate probiotic were added daily from day 1 to day 3 . The pathogenic Vibrio strain was inoculated once at day 3. 
During the challenge tests, the percentage of survival was calculated by counting the number of swimming larvae. At the end of each experiment, Artemia were fixed with Lugol's solution to measure their individual length under binocular magnifying glass fitted with a micrometer (Nikon Eclipse 50i, Japan). The absence of bacteria in the axenic group was monitored at the beginning and at the end of each run of the procedure.

\subsection{Statistical analysis}

Normal distribution and homoscedasticity were obtained in Artemia survival (\%) and length with arcsine and square-root transformation, respectively. The differences between means were compared by analysis of variances and Fisher's test of protected least significant difference by using Statview software package.

\section{Results}

\subsection{Bacterial characterization and antimicrobial activity}

Among the 55 strains of LAB examined for antibacterial activity, 15 were selected for their strong antagonism to Vibrio sp. (Table 1). The diameters of the inhibition zones corresponding to the 15 strains were variable, depending on the indicator strain, but the average was around 13-14 mm for every LAB, except for strain TGO, which appeared poorly antagonistic to some biovars, with the higest cell-free supernatant $\mathrm{pH}$ (4.5). With the other strains however, there was not obvious relationship between antagonistic activity and $\mathrm{pH}$ range (3.9-4.3; Table 1$)$.

A second step of selection was done with the plate test for adhesion. Four strains were highly adhesive to polystyrene, with scores between 1.04 and 1.12 (X6, X4, X2, and O32, Table 1), while four other strains were moderately adherent, and the remaining seven strains were weakly or not adherent.

The 15 LAB were also checked for general phenotypic characterization. All the strains were Gram positive, indole negative, catalase negative, non-motile and non-spore-forming. They grew on MRS broths supplemented with 2, 3 and $6 \% \mathrm{NaCl}$, except strain TGO with $6 \% \mathrm{NaCl}$. They produced caseinase, but they did not produce amylase, lipase, lecithinase, and haemolysin. The enzymatic activity profiles were discriminated with the API Zym System (Supplementary Material, Table S1). The similarity of the enzymatic profiles was estimated after Bray-Curtis index. The highly or moderately adherent strains gathered in the same cluster, while the weakly or not adherent strains were retrieved in a second cluster, except TGO that presented the most dissimilar profile (Supplementary Material, Fig. S2). 


\subsection{Bacterial identification}

The genotypes of the 15 LAB were characterized by the restriction profiles that were obtained with Haelll and Cfo I (Supplementary Material, Fig. S3). Based on this screening, seven strains were selected for sequencing, in comparison with Lactobacillus plantarum B3G, which was previously tested on turbot larvae (Gatesoupe, 1994; Table 2). The restriction fragments delineated a main cluster including strains B3P and X2 (Supplementary Material, Fig. S4), while strain BR743 was less similar. The main cluster corresponded to Lactobacillus casei, and strain BR743 corresponded to Lactobacillus dextrinicus (Haakensen et al., 2009). A second cluster included strain 611, identified as La. Plantarum, and less similar strains: Leuconostoc mesenteroides B31, Leuconstoc sp. TGO, and La. casei BR51, the ARDRA profile of which was apparently dissimilar from those observed with the other representatives of the species (Supplementary Material, Fig. S3), unlike its enzymatic profile that matched within the main cluster of La. casei (Supplementary Material, Fig. S2).

\subsection{Artemia survival and growth}

A mortality peak was observed in axenic Artemia at day 5, without any survivor at day 6 (treatment Art axe; Figure 1). When LAB were not introduced in the culture medium during the first 3 days, the inoculation of $V$. alginolyticus at day 3 advanced the mortality peak at day 4 (treatment Art + VA). In the absence of nutrient enrichment, mean survival rates of 30 and $20 \%$ were obtained at day 6 in the groups treated for the first 3 days with La. casei BR51 and X2, respectively. An average of $10 \%$ survival was also observed at day 6 with Le. mesenteroides B31, but without significant difference with the other cultures that resulted in total mortality in the absence of nutrient supply. The addition of nutrient enrichment increased dramatically the survival of Artemia, which was maintained between 100 and $90 \%$ at day 6 with five of the six LAB strains tested without the pathogen. The survival at day 6 was only $50 \%$ in the group treated with La. Plantarum 611 and the enrichment mix. In the trials with one LAB and $V$. alginolyticus, but without enrichment, the mortality peak was delayed in comparison with the group Art + VA. The most significant differences were observed at day 5 , as survival was still $60 \%$ with La. casei BR51, and $30 \%$ with La. casei X2 or with La. dextrinicus BR743 (Supplementary Material, Table S5). However, every challenge test without enrichment resulted in total mortality at day 6 . By contrast, the enrichment supply maintained the survival at day 6 between 15 and $50 \%$ in the challenges including one of the LAB - 611, B31, BXI, BR51, BR743, and X2, by growing order of survival.

Under axenic conditions, the mean length of dead Artemia at day 6 was $0.41 \pm 0.02 \mathrm{~mm}$ (SD). Growth was stimulated by the introduction of bacteria, even $V$. alginolyticus, which induced a slight growth gain compared to the axenic control $(0.52 \pm 0.03 \mathrm{~mm})$. The growth was further increased with $L A B$ (between $0.67 \pm 0.01 \mathrm{~mm}$ and $0.85 \pm 0.01 \mathrm{~mm}$ with BR51, $\mathrm{X} 2$, B31, BXI, BR743, and 611 , by growing order). The mean weights were significantly different between treatments for each $L A B$, with few exceptions (Supplementary Material, Table S6). The addition of nutrient enrichment to LAB raised the growth of Artemia between $0.93 \pm 0.02 \mathrm{~mm}$ and $1.11 \pm 0.01 \mathrm{~mm}$ with BXI, BR743, B31, BR51, 611, and X2, by growing order. In the presence of $V$. alginolyticus, the six $L A B$ strains increased growth between $0.65 \pm 0.08 \mathrm{~mm}$ and $0.85 \pm 0.01 \mathrm{~mm}$ with BXI, 611, B31, BR51, BR743, and X2 
by growing order. The addition of nutrient enrichment to the challenges with one $L A B$ and the pathogen increased further growth between $0.78 \pm 0.01 \mathrm{~mm}$ and $0.93 \pm 0.02 \mathrm{~mm}$ with BR51, B31, BR743, BXI, 611, and $\mathrm{X} 2$ by growing order.

\section{Discussion and conclusion}

The selection of candidate probiotics among LAB isolated in the hatchery appeared feasible with the simplified screening process that was derived from the scheme proposed by Vine et al. (2006). The production of antimicrobial compounds in LAB cell-free supernatants was tested by diffusion on agar plate cultures of pathogenic Vibrio sp. A variety of strains was thus selected, most of them belonging to the genus Lactobacillus, with representatives of three species, La. casei, La. dextrinicus, and La. plantarum. Two selected isolates belonged to the genus Leuconostoc, but strain TGO was less antagonistic to some test pathogens. The nature of the antimicrobial compounds was not characterized in this study. Most antimicrobial activities of LAB are due to organic acids (Reinheimer et al., 1990) and consequent lowering pH (Tejero-Sariñena et al., 2012), but hydrogen peroxide and bacteriocins are also produced (Dimitonova et al., 2007).

The second step of the selection process was the adhesion test to abiotic surface, which may indicate the potential of LAB to colonize the gut, and to further antagonize pathogens (Servin and Coconnier, 2003). The strains identified as La. casei were adherent except BX1, while the others were weakly or not adherent, except La. plantarum sp. 032 that appeared strongly adherent.

The survival of $L A B$ in seawater is an important factor for candidate probiotics in marine larviculture (Vazquez et al., 2003). All the selected strains grew at 2-6\% $\mathrm{NaCl}$, except Leuconostoc sp. TGO that could not grow at $6 \% \mathrm{NaCl}$. Abriouel et al. (2012) showed that most Lactobacillus and Leuconostoc strains can grow at $6.5 \% \mathrm{NaCl}$.

The enzymatic profiles matched generally with the characteristics of the species La. plantarum (Samolada et al., 1998) and La. casei (Charteris et al., 2001), while confirming the atypical phenotypes of strains $\mathrm{BXI}$ and $\mathrm{O} 32$, whose distinctive adhesiveness was already noted. The genotypic characterization by ARDRA indicated that these two strains belonged to La. casei, and La. plantarum, respectively. Surprisingly, the ARDRA profile of strain BR51 appeared close to those of La. plantarum, though the partial nucleotidic sequence of its $16 \mathrm{~S}$ rRNA gene was identical to that of La. casei B3P, likely due to artifact. The genera Lactobacillus and leuconostoc are recognized as safe, and the attention to virulence factors was limited to check the absence of haemolysin.

LAB are known to produce extracellular products that can inhibit the growth of $V$. alginolyticus in Artemia cultures, likely in synergy with organic acids (Villamil et al., 2003). To further validate the probiotic potential, LAB strains were tested on Artemia. Six strains were selected as representatives of the species and biovars, and they protected Artemia against $V$. alginolyticus, to some extent on condition that nutrient enrichment was provided. The beneficial effect of the enrichment was likely independent from that of the probiotic, as the fatty acids and vitamins brought by the feed are required by Artemia, but 
not by LAB. La. plantarum 611 was the least efficient strains, and Artemia survived less well with this strain, compared to the others. La. plantarum was ruled out, even though strain B3G improved survival in turbot larvae that were challenged against pathogenic Vibrio sp. in a previous experiment (Gatesoupe, 1994). In the present screening bioassay, the other LAB were equivalent in terms of survival of enriched Artemia. La. casei BR51 and $\mathrm{X} 2$ were preferred, as they were efficient even in the absence of nutrient supply. La. casei X2 was finally selected due to the best growth performances of Artemia, with or without the pathogen.

These results confirmed the usefulness of screening strategies for rational selection of candidate probiotics (Vine et al., 2006; Fjellheim et al., 2010; Mahdhi et al., 2012). The present selection process was followed by an application to sea bass larvae (Lamari et al., 2013). La. casei $X 2$ appeared efficient to promote growth in fish larvae, but the incidence on conformation was detrimental, compared to the results obtained with commercial probiotics. Consequently, the present way of selecting candidate probiotics may be valid, but the final evaluation in hatchery conditions remains critical.

\section{Acknowledgements}

The authors would like to thank for financial supports EGIDE (CMCU project FranceTunisia No. 08G 0907), and the Agence Universitaire de la Francophonie (AUF-PSCI No. 6313PS809).

\section{References}

Abriouel H, Benomar N, Cobo A, Caballero N, Fernández Fuentes MA, Pérez-Pulido R, Gálvez A (2012) Characterization of lactic acid bacteria from naturally-fermented Manzanilla Aloreña green table olives. Food Microbiol 32:308-316.

Ben Kahla-Nakbi A, Besbes A, Bakhrouf A, Alcaide E (2007) Characterisation and virulence properties of Vibrio isolates from diseased gilthead sea bream (Sparus aurata) cultured in Tunisia. Bull Eur Ass Fish Pathol 27:90-99.

Chaieb K, Chehab O, Zmantar T, Rouabhia M, Mahdouani K, Bakhrouf A (2007) In vitro effect of $\mathrm{pH}$ and ethanol on biofilm formation by clinical ica-positive Staphylococcus epidermidis strains. Ann Microbiol 57:431-437.

Charteris WP, Kelly PM, Morelli L, Collins JK (2001) Quality control Lactobacillus strains for use with the API $50 \mathrm{CH}$ and API ZYM systems at $37^{\circ} \mathrm{C}$. J Basic Microbiol 41:241-251.

Dimitonova SP, Svetla TD, Julia PS, Boris VB (2007) Antimicrobial activity and protective properties of vaginal lactobacilli from healthy Bulgarian women. Anaerobe 13:178-184. 
Fjellheim AJ, Klinkenberg G, Skjermo J, Aasen IM, Vadstein O (2010) Selection of candidate probionts by two different screening strategies from Atlantic cod (Gadus morhua L.) larvae. Vet Microbiol 144:153-159.

Gatesoupe FJ (1994) Lactic acid bacteria increase the resistance of turbot larvae, Scophthalmus maximus, against pathogenic vibrio. Aquat Living Resour 7:277-282.

Gatesoupe FJ (1999) The use of probiotics in aquaculture. Aquaculture 180:147-165.

Gatesoupe FJ (2002) Probiotic and formaldehyde treatments of Artemia nauplii as food for larval pollack Pollachius pollachius. Aquaculture 212:347-360.

Gomez-Gil B, Roque A, Turnbull JF (2000) The use and selection of probiotic bacteria for use in the culture of larval aquatic organisms. Aquaculture 191:259-270.

Gordon H, Pesti L (1971) The gnotobiotic animal as a tool in the study of host microbial relationships. Bacteriol Rev 35:390-429.

Haakensen M, Dobson CM, Hill JE, Ziola B (2009) Reclassification of Pediococcus dextrinicus (Coster and White 1964) Back 1978 (Approved Lists 1980) as Lactobacillus dextrinicus comb. nov., and emended description of the genus Lactobacillus. Int J Syst Evol Microbiol 59:615-621.

Holzapfel WH, Geisen R, Schillinger U (1995) Biological preservation of foods with reference to protective cultures, bacteriocins and food-grade enzymes. Int J Food Microbiol 24:343-362.

Lambert C, Nicolas JL, Cilia V, Corre S (1998) Vibrio pectenicida sp. nov., a pathogen of scallop (Pecten maximus) larvae. Int J SystBacteriol 48:481-487.

Lamari F, Castex M, Larcher T, Ledevin M, Mazurais D, Bakhrouf A, Gatesoupe FJ (2013) Comparison of the effects of the dietary addition of two lactic acid bacteria on the development and conformation of sea bass larvae, Dicentrarchus labrax, and the influence on associated microbiota. Aquaculture 376-379:137-145.

Mahdhi A, Esteban MA, Hmila Z, Bekir K, Kamoun F, Bakhrouf A, Krifi B (2012) Survival and retention of the probiotic properties of Bacillus sp. strains under marine stress starvation conditions and their potential use as a probiotic in Artemia culture. Res Vet Sci 93:1151-1159.

Marques A, Dhont J, Sorgeloos P, Bossier P (2004) Evaluation of different yeast cell wall mutants and microalgae strains as feed for gnotobiotically-grown brine shrimp Artemia franciscana. J Exp Mar Biol Ecol 312:115-136.

Marques A, Thanh TH, Verstraete W, Dhont J, Sorgeloos P, Bossier P (2006) Use of selected bacteria and yeast to protect gnotobiotic Artemia against different pathogens. $J$ Exp Mar Biol Ecolo 334:20-30. 
Merrifield DL, Dimitroglou A, Foey A, Davies SJ, Baker RR, Bogwald J, Castex M, Ringø E (2010) The current status and future focus of probiotic and prebiotic applications for salmonids. Aquaculture 302:1-18.

Nomoto K (2005) Prevention of infections by probiotics. J Biosci Bioeng100:583-592.

Papamaloni E, Kotzekidou P, Tzanetakis N, Litopoulou-Tzanetaki E (2002) Characterization of Microccocaceae isolated from dry fermented sausage. Food Microbiol 19:441-449.

Reinheimer JA, Demkow MR, Candioti MC (1990) Inhibition of coliform bacteria by lactic acid cultures. Aust J Dairy Tech 45:5-9.

Ringø, E, Gatesoupe FJ (1998) Lactic acid bacteria in fish: a review. Aquaculture 160:177203.

Samolada M, Litopoulou-Tzanetaki E, Xanthopoulos V, Tzanetakis N (1998) Changes in microbial flora during manufacture of a traditional fermented milk from ewe's milk. Food Microbiol 15:43-50.

Servin AL, Coconnier MH (2003) Adhesion of probiotic strains to the intestinal mucosa and interaction with pathogens. Best Pract Res Clin Gastroenterol 17:741-754.

Sorgeloos P, Bossuyt E, Laviña E, Baeza-Mesa M,Persoone G (1977) Decapsulation of Artemia cysts: A simple technique for the improvement of the use of brine shrimp in aquaculture. Aquaculture 12: 311-315.

Tejero-Sariñena S, Barlow J, Costabile A, Gibson GR, Rowland I (2012) In vitro evaluation of the antimicrobial activity of a range of probiotics against pathogens: Evidence for the effects of organic acids. Anaerobe 18: 530-538.

Vazquez JA, Cabo ML, Gonzalez MP, Murado MA (2003) Survival of lactic acid bacteria in seawater: A factorial study. Curr Microbiol 47:508-513.

Villamil L, Figueras A, Planas M, Novoa B (2003) Control of Vibrio alginolyticus in Artemia culture by treatment with bacterial probiotics. Aquaculture 219:43-56.

Vine NG, Leukes WD, Kaiser H (2006) Probiotics in marine larviculture. FEMS Microbiol Rev 30:404-427.

Wang YB (2007) Effect of probiotics on growth performance and digestive enzyme activity of the shrimp Penaeus vannamei. Aquaculture 269:259-264.

WHO (World Health Organization) (2006) Report of a joint FAO/OIE/WHO expert consultation on antimicrobial use in aquaculture and antimicrobial resistance: Seoul, Republic of Korea, 13-16 June 2006, WHO Press, Geneva. 
Table 1. Antagonistic activity and adhesion score of the LAB selected as candidate probiotics. The strains were ranked by descending order of adhesion score, which was estimated by the Microtitre-plate test (optical density at $570 \mathrm{~nm}$ ). The antagonistic activity was expressed as the diameter ( $\mathrm{mm} \pm \mathrm{s}$.d.) of the mean inhibition zone in the agar plates inoculated with Vibrio sp. indicator strains.

\begin{tabular}{|c|c|c|c|c|c|c|c|c|c|c|c|c|}
\hline \multirow[t]{3}{*}{ LAB } & \multirow{3}{*}{$\begin{array}{l}\text { Cell-free } \\
\text { supernatant } \\
\text { pH }\end{array}$} & \multicolumn{9}{|c|}{ Antagonistic activity versus Vibrio sp. indicator strains } & \multirow{3}{*}{$\begin{array}{l}\text { Average } \\
\text { activity }\end{array}$} & \multirow{3}{*}{$\begin{array}{c}\text { Adhesion } \\
\text { score }\end{array}$} \\
\hline & & \multicolumn{5}{|c|}{ Vibrio alginolyticus } & \multicolumn{4}{|c|}{ Vibrio parahaemolyticus } & & \\
\hline & & $\mathrm{E} 1^{\S}$ & E3* & $55 \mathrm{j}$ & $32 \mathrm{j}$ & $30 \mathrm{j}$ & $\mathrm{E} 2^{\$}$ & $30 \mathrm{v}$ & $53 \mathrm{v}$ & $12 \mathrm{pv}$ & & \\
\hline X6 & 4.00 & $14.6 \pm 0.5$ & $14.0 \pm 0.0$ & $14.3 \pm 0.5$ & $12.3 \pm 0.5$ & $13.0 \pm 0.5$ & $12.6 \pm 0.5$ & $14.6 \pm 0.5$ & $15.0 \pm 1.0$ & $12.6 \pm 0.5$ & $13.7 \pm 1.0$ & $1.12 \pm 0.11$ \\
\hline $\mathrm{X} 4$ & 3.96 & $14.0 \pm 0.0$ & $13.6 \pm 0.5$ & $15.0 \pm 0.0$ & $14.3 \pm 0.5$ & $14.6 \pm 0.5$ & $13.3 \pm 0.5$ & $13.0 \pm 0.0$ & $17.0 \pm 1.0$ & $13.6 \pm 0.5$ & $14.0 \pm 0.6$ & $1.07 \pm 0.13$ \\
\hline $\mathrm{X} 2$ & 3.93 & $14.0 \pm 0.0$ & $14.6 \pm 0.5$ & $14.3 \pm 0.5$ & $13.3 \pm 0.5$ & $14.6 \pm 0.5$ & $13.6 \pm 0.5$ & $13.3 \pm 0.5$ & $15.0 \pm 0.0$ & $13.6 \pm 0.5$ & $14.3 \pm 1.2$ & $1.08 \pm 0.10$ \\
\hline $\mathrm{O} 32$ & 3.94 & $14.3 \pm 0.5$ & $14.0 \pm 0.0$ & $13.0 \pm 0.0$ & $13.3 \pm 0.5$ & $13.0 \pm 0.5$ & $13.0 \pm 1.0$ & $13.6 \pm 0.5$ & $14.6 \pm 0.5$ & $13.3 \pm 0.5$ & $13.6 \pm 0.6$ & $1.04 \pm 0.05$ \\
\hline BR51 & 3.97 & $15.0 \pm 1.0$ & $14.0 \pm 0.0$ & $13.0 \pm 1.0$ & $13.3 \pm 0.5$ & $12.6 \pm 0.5$ & $13.0 \pm 1.0$ & $12.6 \pm 0.5$ & $14.6 \pm 0.5$ & $12.0 \pm 1.0$ & $13.3 \pm 1.0$ & $0.93 \pm 0.02$ \\
\hline $\mathrm{X} 5$ & 4.07 & $14.6 \pm 0.5$ & $13.6 \pm 0.5$ & $14.6 \pm 0.5$ & $13.3 \pm 0.5$ & $13.3 \pm 0.5$ & $12.6 \pm 0.5$ & $14.6 \pm 0.5$ & $15.6 \pm 1.1$ & $12.6 \pm 0.5$ & $13.9 \pm 1.0$ & $0.84 \pm 0.09$ \\
\hline $\mathrm{F} 2 \mathrm{P}$ & 3.97 & $15.0 \pm 0.0$ & $13.6 \pm 0.5$ & $14.0 \pm 1.0$ & $12.0 \pm 1.0$ & $12.6 \pm 1.0$ & $13.6 \pm 0.5$ & $13.3 \pm 0.5$ & $15.6 \pm 1.1$ & $12.6 \pm 0.5$ & $13.6 \pm 1.2$ & $0.76 \pm 0.02$ \\
\hline B3P & 4.27 & $15.3 \pm 0.5$ & $13.3 \pm 0.5$ & $15.0 \pm 0.0$ & $14.0 \pm 1.0$ & $13.6 \pm 1.0$ & $13.3 \pm 0.5$ & $14.0 \pm 1.0$ & $15.0 \pm 1.0$ & $12.3 \pm 0.5$ & $14.0 \pm 1.0$ & $0.74 \pm 0.07$ \\
\hline B31 & 4.13 & $15.6 \pm 0.5$ & $13.3 \pm 0.5$ & $14.3 \pm 0.5$ & $13.3 \pm 0.5$ & $13.0 \pm 0.5$ & $13.3 \pm 0.5$ & $13.3 \pm 0.5$ & $14.3 \pm 0.5$ & $12.0 \pm 1.0$ & $13.6 \pm 1.0$ & $0.22 \pm 0.01$ \\
\hline BR743 & 3.91 & $14.0 \pm 0.0$ & $13.6 \pm 0.5$ & $14.3 \pm 0.5$ & $14.3 \pm 0.5$ & $14.6 \pm 0.5$ & $13.3 \pm 0.5$ & $14.0 \pm 1.0$ & $15.3 \pm 0.5$ & $13.3 \pm 0.5$ & $14.1 \pm 0.6$ & $0.11 \pm 0.02$ \\
\hline BR611 & 4.02 & $10.3 \pm 0.5$ & $10.6 \pm 0.5$ & $15.3 \pm 0.5$ & $12.6 \pm 0.5$ & $13.0 \pm 0.5$ & $9.3 \pm 0.5$ & $14.6 \pm 0.5$ & $17.0 \pm 1.0$ & $13.0 \pm 1.0$ & $12.9 \pm 2.5$ & $0.09 \pm 0.02$ \\
\hline 611 & 3.88 & $14.0 \pm 0.0$ & $14.0 \pm 0.0$ & $15.0 \pm 1.0$ & $14.6 \pm 0.5$ & $14.6 \pm 0.5$ & $13.3 \pm 0.5$ & $15.0 \pm 1.0$ & $15.6 \pm 1.1$ & $13.6 \pm 0.5$ & $14.4 \pm 0.7$ & $0.08 \pm 0.02$ \\
\hline XIG & 3.90 & $14.6 \pm 0.5$ & $13.6 \pm 0.5$ & $14.0 \pm 1.0$ & $12.3 \pm 0.5$ & $12.3 \pm 0.5$ & $13.0 \pm 0.0$ & $14.3 \pm 0.5$ & $16.0 \pm 1.0$ & $13.0 \pm 0.0$ & $13.7 \pm 1.2$ & $0.08 \pm 0.03$ \\
\hline BXI & 4.03 & $15.6 \pm 0.5$ & $13.6 \pm 0.5$ & $15.0 \pm 0.0$ & $14.0 \pm 1.0$ & $13.3 \pm 1.0$ & $13.0 \pm 0.0$ & $14.3 \pm 1.1$ & $15.0 \pm 1.0$ & $12.0 \pm 1.0$ & $14.0 \pm 1.1$ & $0.06 \pm 0.01$ \\
\hline TGO & 4.48 & $15.3 \pm 0.5$ & $13.3 \pm 0.5$ & $10.6 \pm 0.5$ & $8.3 \pm 0.5$ & $8.3 \pm 0.5$ & $13.0 \pm 0.0$ & $8.6 \pm 0.5$ & $8.3 \pm 0.5$ & $8.3 \pm 0.5$ & $10.4 \pm 2.7$ & $0.04 \pm 0.01$ \\
\hline
\end{tabular}


Table 2. Bacterial isolates selected as representatives of the different clusters obtained after restriction analysis of the $16 \mathrm{~S}$ rRNA gene*, and subsequent partial sequencing

\begin{tabular}{|c|c|c|c|}
\hline Lactobacilli isolates & Identification & Accession number & $\%$ identity \\
\hline $\mathrm{BR} 51^{\S}$ & Lactobacillus casei BR51 & HF562841 & \\
\hline \multirow[t]{2}{*}{$\mathrm{X} 2$} & Lactobacillus casei X2 & HF562840 & \\
\hline & & & 99.8 \\
\hline BR743 & Lactobacillus dextrinicus BR743 & FM877685 & \\
\hline 611 & Lactobacillus plantarum 611 & HF562838 & \\
\hline \multirow[t]{2}{*}{$\mathrm{B} 3 \mathrm{G}^{*}$} & Lactobacillus plantarum $\mathrm{B} 3 \mathrm{G}$ & HF562839 & \\
\hline & & & 99.9 \\
\hline B31 & Leuconostocmesenteroides B31 & HF562842 & \\
\hline \multirow[t]{2}{*}{ TGO } & Leuconostoc sp. TGO & HF562843 & \\
\hline & & & 99.1 \\
\hline
\end{tabular}

* Lactobacillus plantarum B3G was added as a reference strain, which was previously tested (Gatesoupe, 1994)

§Sequence $100 \%$ identical with that of strain B3P on a read length of $913 \mathrm{bp}$ 


\section{Figures}

Figure 1 : Survival of Artemia under axenic (Art axe) and gnotobiotic conditions (\% \pm SD). Six LAB strains were tested: 611, BR743, BR51, X2, BX1, and B31 (figures 1a, 1a, 1c, 1d, 1e and $1 \mathrm{f}$, respectively), with or without addition of enrichment feed (A). The nauplii were challenged with $V$. alginolyticus (VA), in the presence or absence of the LAB, with or without the enrichment feed.
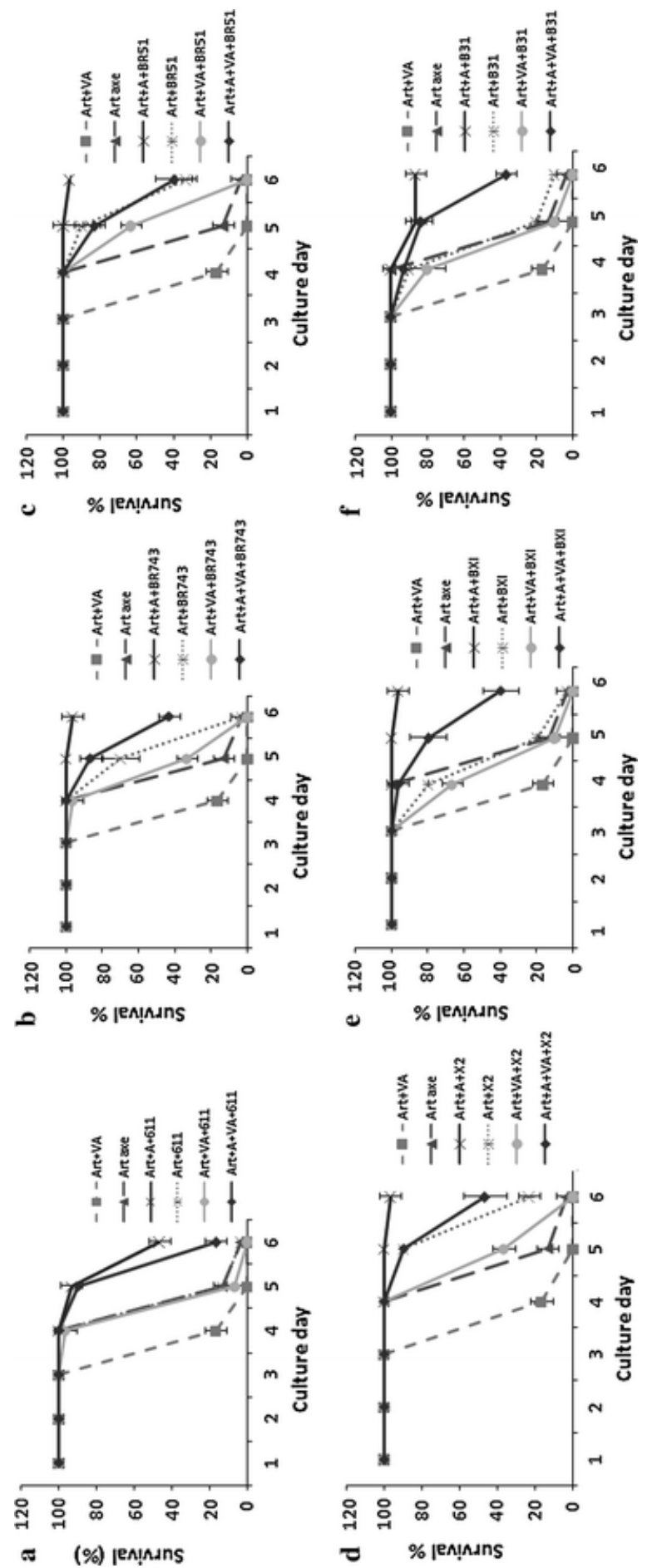
Figure 2 : Mean length ( $\mathrm{mm} \pm \mathrm{SD}$ ) of 6 days-old Artemia in axenic (Art axe), monoxenic cultures (LAB strain 611, BR743, BR51, X2, BX1, or B31, or V. alginolyticus VA), and dixenic cultures (LAB strain + VA), with or without nutrient enrichment $(A)$.

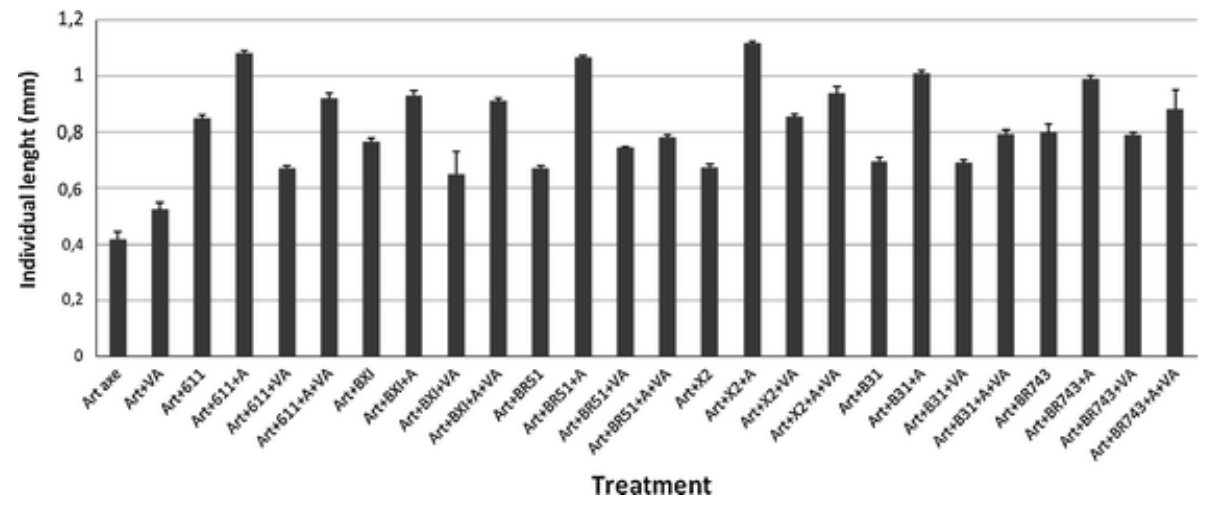




\section{Supplementary material}

Table S1. Enzymatic activities corresponding to the LAB strains tested on API ZYM strips; the cluster analysis based on the BrayCurtis similarity of these profiles was illustrated in Figure S2.

\begin{tabular}{|c|c|c|c|c|c|c|c|c|c|c|c|c|c|c|c|c|c|c|c|}
\hline Enzymes & 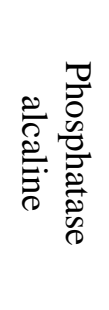 & 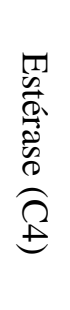 & 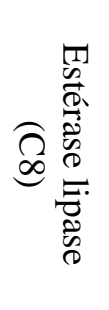 & 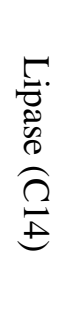 & 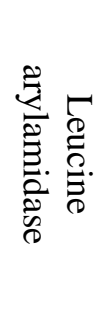 & 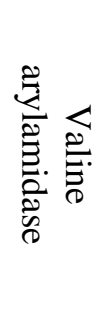 & 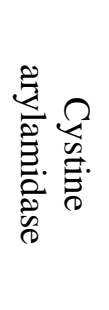 & $\begin{array}{l}\vec{\Xi} \\
\overrightarrow{0} \\
0 \\
0\end{array}$ & 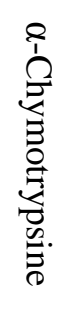 & 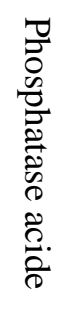 & 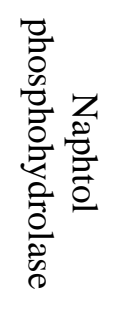 & 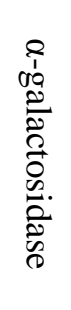 & 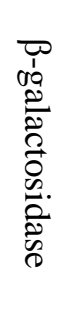 & 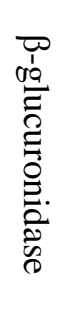 & 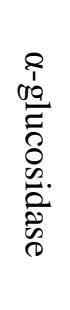 & 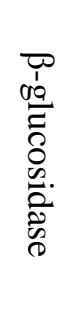 & 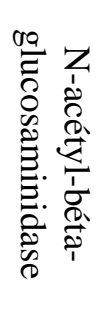 & 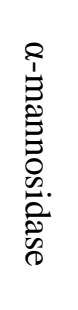 & 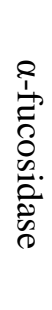 \\
\hline B31 & 2 & 1 & 1 & 0 & 5 & 5 & 1 & 0 & 0 & 4 & 2 & 2 & 5 & 0 & 5 & 5 & 5 & 0 & 0 \\
\hline 611 & 2 & 1 & 0 & 0 & 5 & 5 & 3 & 0 & 0 & 5 & 3 & 0 & 5 & 0 & 5 & 4 & 5 & 0 & 0 \\
\hline $\mathrm{X} 2$ & 1 & 2 & 1 & 0 & 5 & 5 & 4 & 0 & 4 & 5 & 4 & 0 & 5 & 0 & 5 & 5 & 1 & 0 & 1 \\
\hline$F 2 p$ & 2 & 2 & 2 & 0 & 5 & 5 & 4 & 0 & 3 & 5 & 5 & 2 & 5 & 3 & 5 & 4 & 0 & 0 & 1 \\
\hline BR611 & 2 & 1 & 1 & 0 & 5 & 5 & 4 & 0 & 0 & 5 & 4 & 0 & 5 & 0 & 5 & 5 & 5 & 0 & 0 \\
\hline X6 & 1 & 1 & 1 & 0 & 5 & 5 & 3 & 0 & 3 & 4 & 4 & 0 & 5 & 0 & 5 & 4 & 3 & 0 & 2 \\
\hline $\mathrm{O} 32$ & 3 & 3 & 3 & 0 & 5 & 5 & 4 & 0 & 3 & 5 & 4 & 0 & 5 & 0 & 5 & 4 & 1 & 0 & 2 \\
\hline BXI & 3 & 0 & 0 & 0 & 5 & 4 & 0 & 0 & 0 & 5 & 3 & 4 & 5 & 0 & 5 & 4 & 5 & 0 & 0 \\
\hline $\mathrm{X} 4$ & 3 & 3 & 2 & 0 & 5 & 5 & 3 & 0 & 3 & 5 & 4 & 0 & 4 & 0 & 5 & 4 & 0 & 0 & 2 \\
\hline $\mathrm{XIG}$ & 3 & 1 & 1 & 0 & 5 & 5 & 4 & 0 & 0 & 5 & 4 & 0 & 5 & 0 & 5 & 5 & 5 & 0 & 0 \\
\hline BR743 & 2 & 0 & 0 & 0 & 5 & 5 & 3 & 0 & 0 & 4 & 3 & 2 & 5 & 0 & 4 & 4 & 5 & 0 & 0 \\
\hline B3p & 1 & 1 & 1 & 0 & 5 & 5 & 2 & 0 & 3 & 5 & 4 & 0 & 5 & 0 & 5 & 4 & 1 & 0 & 1 \\
\hline $\mathrm{X} 5$ & 2 & 2 & 2 & 0 & 5 & 5 & 5 & 0 & 4 & 5 & 4 & 3 & 5 & 3 & 5 & 4 & 1 & 0 & 1 \\
\hline BR51 & 2 & 2 & 2 & 0 & 5 & 5 & 4 & 0 & 3 & 4 & 4 & 0 & 5 & 0 & 5 & 2 & 0 & 0 & 2 \\
\hline TGO & 2 & 2 & 0 & 0 & 2 & 2 & 0 & 0 & 0 & 5 & 3 & 0 & 5 & 0 & 5 & 2 & 0 & 0 & 2 \\
\hline
\end{tabular}

0: no activity; 1: liberation of $5 \mathrm{nmol} ; 2: 10 \mathrm{nmol} ; 3: 20 \mathrm{nmol}$; 4: $30 \mathrm{nmol}$ and 5: $40 \mathrm{nmol}$. 


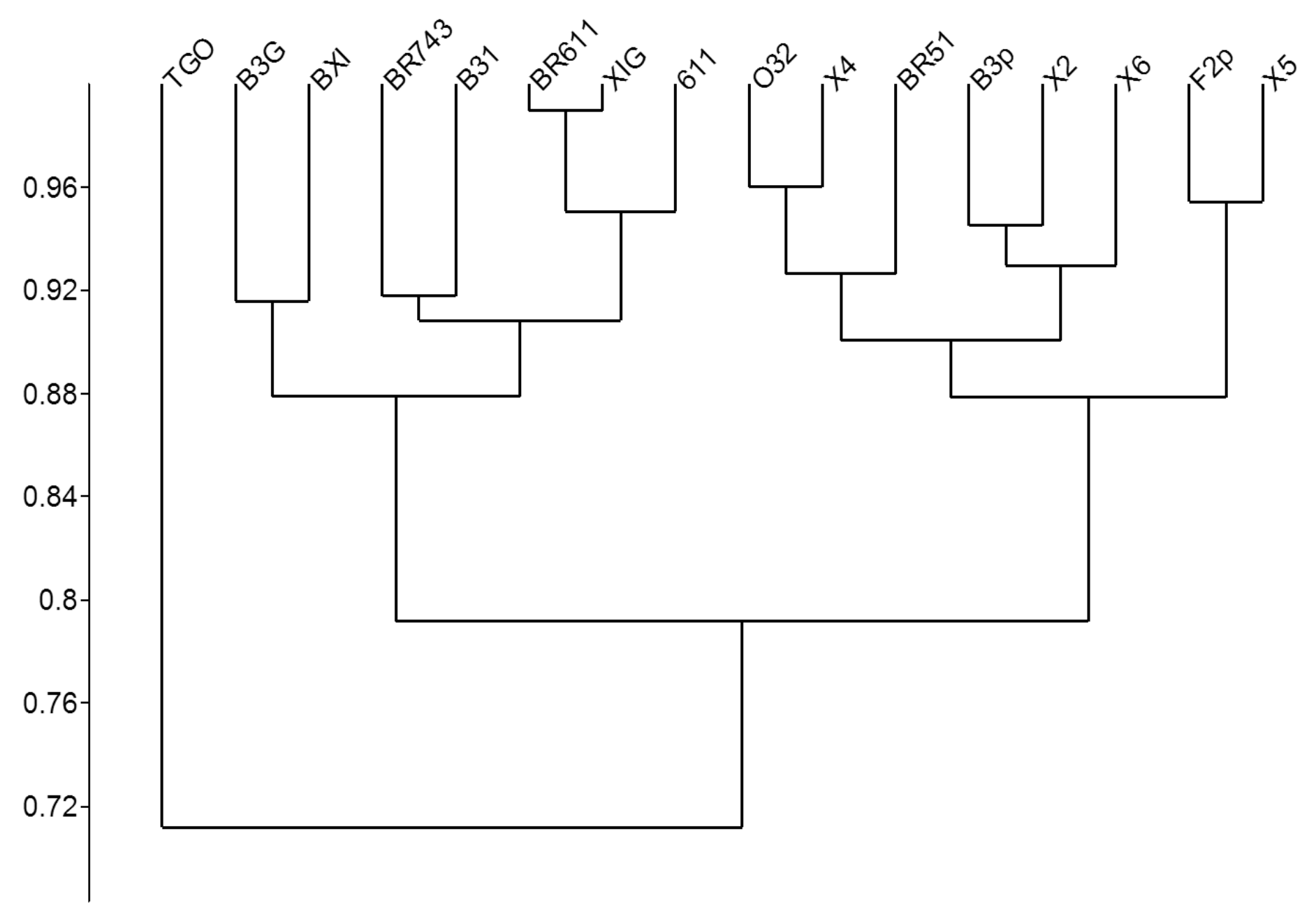

Bray-Curtis similarity

Figure S2 - Cluster analysis obtained after Bray-Curtis similarity of the API ZYM profiles of the LAB strains (see Table S1) 
Figure S3. Restriction patterns obtained after digestion with Hae III and Cfo I of PCR products from the 16S RNA gene of the LAB strains (M: SmartLadder, Eurogenetec).

\section{Method:}

The LAB were cultivated in MRS agar and incubated at $37^{\circ} \mathrm{C}$ for $24 \mathrm{~h}$. The colonies were collected, and suspended in $200 \mu \mathrm{L}$ lysis solution (10 mM Tris-HCl, $1 \mathrm{mM}$ EDTA, 1\% Triton X-100), heated for $5 \mathrm{~min}$ at $100^{\circ} \mathrm{C}$, and immediately cooled on ice. After adding $200 \mu \mathrm{L}$ glass beads (Sigma G4649), the tubes were beaten for 10 min. DNA was then purified by chloroform extraction and ethanol precipitation. The air-dried DNA pellet was resuspended in DNAse-free MiliQ water. The 16S rRNA gene was amplified by polymerase chain reaction (PCR) with the universal primers SA-dir (5'-AGAGTTTGATCATGGCTCAG-3') and S17-rev (5'-GTTACCTTGTTACGACTT-3') as described by Lambert et al. (1998), using a thermocycler Techne TC-512. The PCR conditions were as follows: initial denaturation at $950 \mathrm{C}$ for $3 \mathrm{~min}$, followed by 25 cycles of denaturation at $940 \mathrm{C}$ for $30 \mathrm{~s}$; annealing at $52 \mathrm{oC}$ for $1 \mathrm{~min}$; extension at $72 \mathrm{oC}$ for $1.5 \mathrm{~min}$, and a final extension at $720 \mathrm{C}$ for $5 \mathrm{~min}$. The PCR products were deposited into wells of agarose gel (1.5\%, wt vol-1) with ethidium bromide for staining, plus one well with DNA base-pair (bp) ladder, and the electrophoresis was run at $100 \mathrm{~V}$. The resulting migration was visualized under UV light. To characterize the amplicons by amplified ribosomal DNA restriction analysis (ARDRA), 4- $\mu \mathrm{l}$ aliquots of each PCR product were added to $5.5 \mu \mathrm{l}$ of buffered premix with one of the two restriction enzymes, Hae III or Cfo I (Gatesoupe, 2002). The incubation was carried out for $4 \mathrm{~h}$ at $37^{\circ} \mathrm{C}$. The restriction products were separated by electrophoresis on agarose gel, in conditions similar to those for controlling PCR products. The selective migration was visualized under ChemiDoc XRS System (BioRad.) The sizes of DNA fragments were estimated using a 100-bp DNA ladder (SmartLadder, Eurogenetec).

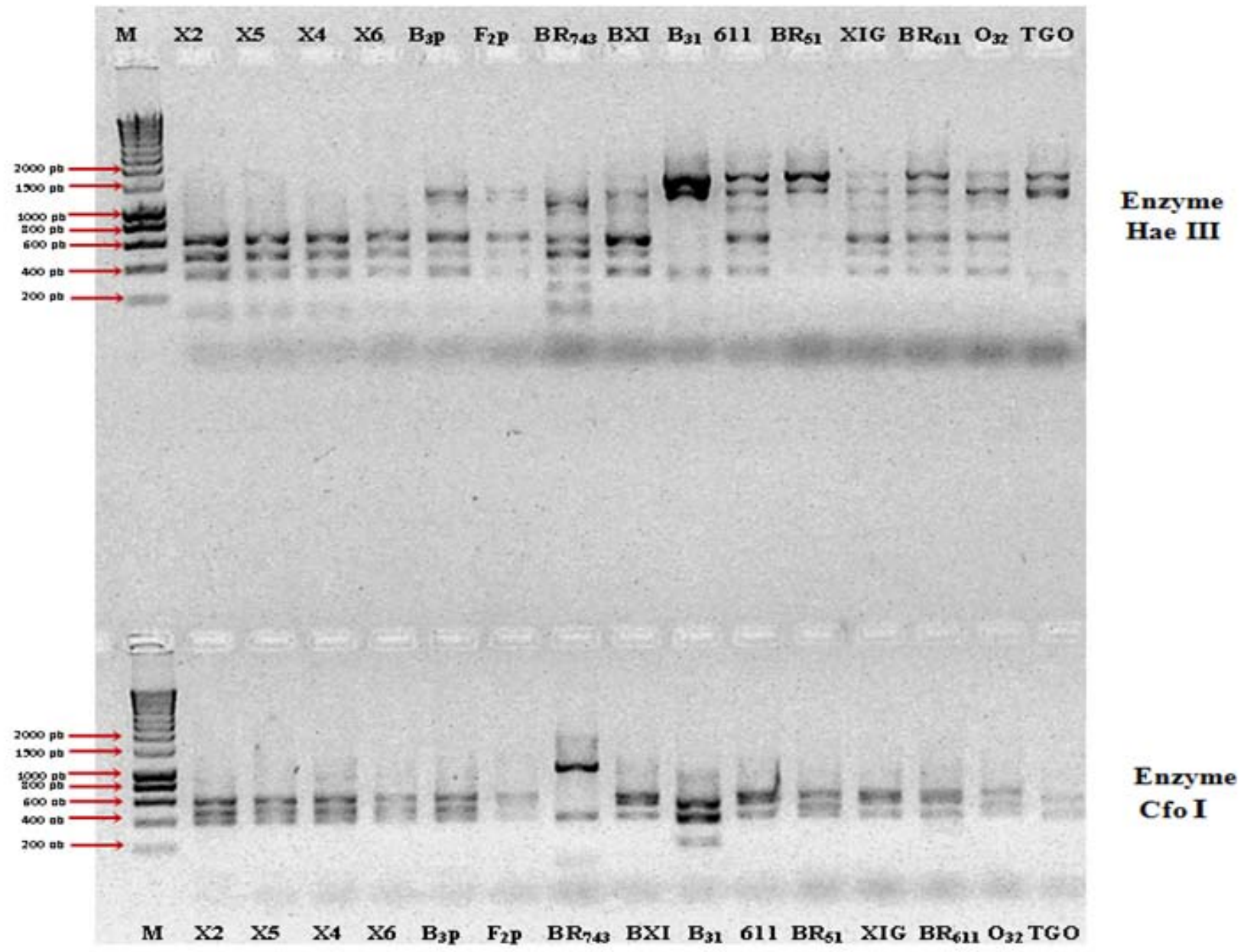




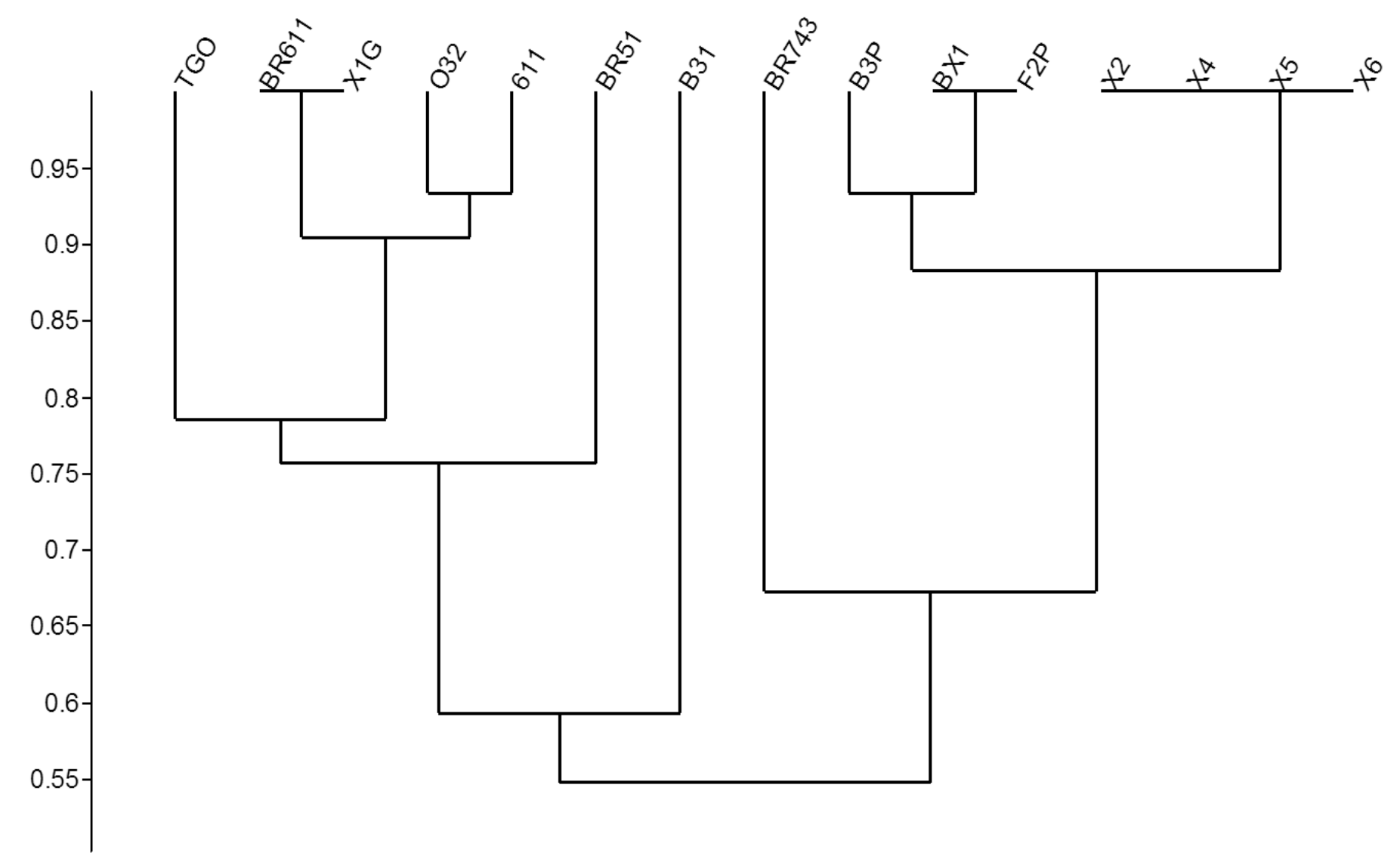

Dice similarity

Figure S4 - Cluster analysis obtained after Dice similarity of the ARDRA profiles of the LAB strains (see Figure S3) 
Table S5. Pairwise comparisons among the survival rates of Artemia measured at day 5 with the different treatments, with or without each strain lactic acid bacteria (611; X2; BR743: BXI; BR51 and B31; Fig. 1).

\begin{tabular}{|c|c|c|c|c|c|c|c|}
\hline & & Art+VA & Art axe & Art+A+611 & Art+611 & Art+VA+611 & $A r t+A+V A+611$ \\
\hline \multirow{6}{*}{ Strain 611} & Art+VA & - & 0.2012 & $<0.0001^{*}$ & 0.2012 & 0.5118 & $<0.0001^{*}$ \\
\hline & Art axe & & - & $<0.0001^{*}$ & 0.000 & 0.5118 & $<0.0001^{*}$ \\
\hline & Art+A+611 & & & - & $<0.0001^{*}$ & $<0.0001^{*}$ & 0.1541 \\
\hline & Art+611 & & & & - & 0.5118 & $<0.0001^{*}$ \\
\hline & Art+VA+611 & & & & & - & $<0.0001^{*}$ \\
\hline & Art+A+VA+611 & & & & & & - \\
\hline \multirow{7}{*}{ Strain X2 } & & Art+VA & Art axe & $A r t+A+X 2$ & Art+X2 & Art+VA+X2 & $A r t+A+V A+X 2$ \\
\hline & Art+VA & - & $0.0006 *$ & $<0.0001^{*}$ & $<0.0001^{*}$ & $<0.0001^{*}$ & $<0.0001^{*}$ \\
\hline & Art axe & & - & $<0.0001^{*}$ & $<0.0001^{*}$ & $<0.0001^{*}$ & $<0.0001^{*}$ \\
\hline & $A r t+A+X 2$ & & & - & $<0.0001^{*}$ & $<0.0001^{*}$ & $<0.0001^{*}$ \\
\hline & Art+X2 & & & & - & $<0.0001^{*}$ & 0.000 \\
\hline & Art+VA+X2 & & & & & - & $<0.0001^{*}$ \\
\hline & $A r t+A+V A+X 2$ & & & & & & - \\
\hline \multirow{7}{*}{$\begin{array}{l}\text { Strain } \\
\text { BR743 }\end{array}$} & & Art+VA & Art axe & Art+A+BR743 & Art+BR743 & Art+VA+BR743 & Art+A+VA+BR743 \\
\hline & Art+VA & - & 0.700 & $<0.0001^{*}$ & $<0.0001^{*}$ & $0.0003^{*}$ & $<0.0001^{*}$ \\
\hline & Art axe & & - & $<0.0001^{*}$ & $<0.0001^{*}$ & $0.104^{*}$ & $<0.0001^{*}$ \\
\hline & Art+A+BR743 & & & - & $<0.0001^{*}$ & $<0.0001^{*}$ & $<0.0001^{*}$ \\
\hline & Art+BR743 & & & & - & $<0.0001^{*}$ & $0.0015^{*}$ \\
\hline & Art+VA+BR743 & & & & & - & $<0.0001^{*}$ \\
\hline & $A r t+A+V A+B R 743$ & & & & & & - \\
\hline \multirow{7}{*}{ Strain BXI } & & Art+VA & Art axe & Art+A+BXI & Art+BXI & Art+VA+BXI & $A r t+A+V A+B X I$ \\
\hline & Art+VA & - & 0.0758 & $<0.0001^{*}$ & $0.0130 *$ & 0.1706 & $<0.0001^{*}$ \\
\hline & Art axe & & - & $<0.0001^{*}$ & 0.3504 & 0.6358 & $<0.0001^{*}$ \\
\hline & Art+A+BXI & & & - & $<0.0001^{*}$ & $<0.0001^{*}$ & $<0.0001^{*}$ \\
\hline & Art+BXI & & & & - & 0.1706 & $<0.0001^{*}$ \\
\hline & Art+VA+BXI & & & & & - & $<0.0001^{*}$ \\
\hline & $A r t+A+V A+B X I$ & & & & & & - \\
\hline \multirow{7}{*}{ Strain BR51 } & & Art+VA & Art axe & Art+A+BR51 & Art+BR51 & Art+VA+BR51 & Art+A+VA+BR51 \\
\hline & Art+VA & - & 0.2889 & $<0.0001^{*}$ & $<0.0001^{*}$ & $<0.0001^{*}$ & $<0.0001^{*}$ \\
\hline & Art axe & & - & $<0.0001^{*}$ & $<0.0001^{*}$ & $0.0006^{*}$ & $<0.0001^{*}$ \\
\hline & Art+A+BR51 & & & - & $0.0106 *$ & $<0.0001^{*}$ & $0.0004^{*}$ \\
\hline & Art+BR51 & & & & - & $0.0010^{*}$ & 0.1012 \\
\hline & Art+VA+BR51 & & & & & - & $0.0254^{*}$ \\
\hline & Art+A+VA+BR51 & & & & & & - \\
\hline \multirow{7}{*}{ Strain B31 } & & Art+VA & Art axe & Art+A+B31 & Art+B31 & Art+VA+B31 & $A r t+A+V A+B 31$ \\
\hline & Art+VA & - & 0.0910 & $<0.0001^{*}$ & $0.0174^{*}$ & 0.1934 & $<0.0001^{*}$ \\
\hline & Art axe & & - & $<0.0001^{*}$ & 0.3764 & 0.6542 & $<0.0001^{*}$ \\
\hline & Art+A+B31 & & & - & $<0.0001^{*}$ & $<0.0001^{*}$ & 0.4000 \\
\hline & Art+B31 & & & & - & 0.1934 & $<0.0001^{*}$ \\
\hline & Art+VA+B31 & & & & & - & $<0.0001 *$ \\
\hline & Art+A+VA+B31 & & & & & & - \\
\hline
\end{tabular}

* Significant difference, after $p$ computed from arcsine transformed data, with post-hoc Fisher's test 
Table S6. Pairwise comparisons among the mean weights of Artemia measured at day 6 with the different treatments, with or without each strain lactic acid bacteria (611; X2; BR743: BXI; BR51 and B31; Fig. 2).

\begin{tabular}{|c|c|c|c|c|c|c|c|}
\hline & & Art+VA & Art axe & Art+A+611 & Art+611 & Art+VA+611 & $A r t+A+V A+611$ \\
\hline \multirow{6}{*}{ Strain 611} & Art+VA & - & $<0.0001^{*}$ & $<0.0001^{*}$ & $<0.0001^{*}$ & $<0.0001^{*}$ & $<0.0001^{*}$ \\
\hline & Art axe & & - & $<0.0001^{*}$ & $<0.0001^{*}$ & $<0.0001^{*}$ & $<0.0001^{*}$ \\
\hline & $A r t+A+611$ & & & - & $<0.0001^{*}$ & $<0.0001^{*}$ & $<0.0001^{*}$ \\
\hline & Art+611 & & & & - & $<0.0001^{*}$ & $<0.0001^{*}$ \\
\hline & Art+VA+611 & & & & & - & $<0.0001^{*}$ \\
\hline & Art+A+VA+611 & & & & & & - \\
\hline \multirow{7}{*}{ Strain X2 } & & Art+VA & Art axe & Art+A+X2 & Art+X2 & Art+VA+X2 & $A r t+A+V A+X 2$ \\
\hline & Art+VA & - & $0.001^{*}$ & $<0.0001^{*}$ & $<0.0001^{*}$ & $<0.0001^{*}$ & $<0.0001^{*}$ \\
\hline & Art axe & & - & $<0.0001^{*}$ & $<0.0001^{*}$ & $<0.0001^{*}$ & $<0.0001^{*}$ \\
\hline & $A r t+A+X 2$ & & & - & $<0.0001^{*}$ & $<0.0001^{*}$ & $<0.0001^{*}$ \\
\hline & Art+X2 & & & & - & $<0.0001^{*}$ & $<0.0001^{*}$ \\
\hline & $A r t+V A+X 2$ & & & & & - & 0.3624 \\
\hline & Art+A+VA+X2 & & & & & & - \\
\hline \multirow{7}{*}{$\begin{array}{l}\text { Strain } \\
\text { BR743 }\end{array}$} & & Art+VA & Art axe & Art+A+BR743 & Art+BR743 & Art+VA+BR743 & Art+A+VA+BR743 \\
\hline & Art+VA & - & $0.0031^{*}$ & $<0.0001^{*}$ & $<0.0001^{*}$ & $<0.0001^{*}$ & $<0.0001^{*}$ \\
\hline & Art axe & & - & $<0.0001^{*}$ & $<0.0001^{*}$ & $<0.0001^{*}$ & $<0.0001^{*}$ \\
\hline & Art+A+BR743 & & & - & $<0.0001^{*}$ & $<0.0001^{*}$ & $0.0025^{*}$ \\
\hline & Art+BR743 & & & & - & 0.8213 & $0.0137^{*}$ \\
\hline & Art+VA+BR743 & & & & & - & $0.0089 *$ \\
\hline & Art+A+VA+BR743 & & & & & & - \\
\hline \multirow{7}{*}{ Strain BXI } & & Art+VA & Art axe & $A r t+A+B X I$ & Art+BXI & Art+VA+BXI & $A r t+A+V A+B X I$ \\
\hline & Art+VA & - & $0.0043^{*}$ & $<0.0001^{*}$ & $<0.0001^{*}$ & $0.0013^{*}$ & $<0.0001^{*}$ \\
\hline & Art axe & & - & $<0.0001^{*}$ & $<0.0001^{*}$ & $<0.0001^{*}$ & $<0.0001^{*}$ \\
\hline & $A r t+A+B X I$ & & & - & $0.0002 *$ & $<0.0001^{*}$ & 0.5226 \\
\hline & Art+BXI & & & & - & $0.0023^{*}$ & $0.0005^{*}$ \\
\hline & Art+VA+BXI & & & & & - & $<0.0001^{*}$ \\
\hline & $A r t+A+V A+B X I$ & & & & & & - \\
\hline \multirow{7}{*}{ Strain BR51 } & & Art+VA & Art axe & Art+A+BR51 & Art+BR51 & Art+VA+BR51 & Art+A+VA+BR51 \\
\hline & Art+VA & - & $<0.0001^{*}$ & $<0.0001^{*}$ & $<0.0001^{*}$ & $<0.0001^{*}$ & $<0.0001^{*}$ \\
\hline & Art axe & & - & $<0.0001^{*}$ & $<0.0001^{*}$ & $<0.0001^{*}$ & $<0.0001^{*}$ \\
\hline & Art+A+BR51 & & & - & $<0.0001^{*}$ & $<0.0001^{*}$ & $<0.0001^{*}$ \\
\hline & Art+BR51 & & & & - & $0.0002^{*}$ & $<0.0001^{*}$ \\
\hline & Art+VA+BR51 & & & & & - & $0.0215^{*}$ \\
\hline & Art+A+VA+BR51 & & & & & & - \\
\hline \multirow{7}{*}{ Strain B31 } & & Art+VA & Art axe & Art+A+B31 & Art+B31 & Art+VA+B31 & Art+A+VA+B31 \\
\hline & Art+VA & - & $<0.0001^{*}$ & $<0.0001^{*}$ & $<0.0001^{*}$ & $<0.0001^{*}$ & $<0.0001^{*}$ \\
\hline & Art axe & & - & $<0.0001^{*}$ & $<0.0001^{*}$ & $<0.0001^{*}$ & $<0.0001^{*}$ \\
\hline & Art+A+B31 & & & - & $<0.0001^{*}$ & $<0.0001^{*}$ & $<0.0001^{*}$ \\
\hline & Art+B31 & & & & - & 0.8322 & $<0.0001^{*}$ \\
\hline & Art+VA+B31 & & & & & - & $<0.0001^{*}$ \\
\hline & $A r t+A+V A+B 31$ & & & & & & - \\
\hline
\end{tabular}

*Significant difference, after $p$ computed from square-root transformed data, with post-hoc Fisher's test 